\title{
Types of Pleasures Occurring through Paid Sexual Performances among Women Offering Escort Services
}

\author{
Jacqueline Comte \\ École de Service Social (School of Social Service), Université Laval, Canada \\ E-mail: comte.jacqueline@gmail.com
}

Received: November 8, 2016 Accepted: December 20, 2016 Published: December 27, 2016

doi: 10.5296/jsss.v4i1.10279 URL: http://dx.doi.org/10.5296/jsss.v4i1.10279

\begin{abstract}
Even though offering sexual services implies for service providers that they have to deal directly with sexuality, research rarely focuses on their representations and emotional experience of sexuality. In order to explore both of these aspects, 16 women who either were offering or had offered escort services were individually met for two semi-directed interviews of about 90 minutes each. Most participants either pursued or accepted sexual pleasure in their interaction with clients, while a few others rather avoided it. In this article, I will first review the skills participants considered necessary for a good work performance (self-presentation as beautiful, feminine and sexy; listening skills and empathy; sexual competence). Following this, I will present the experiences of different types of pleasure they identified (regarding work well done; resulting from performing sexually; feeling sexual pleasure) and compare these experiences as well as the representations those pursuing or accepting sexual pleasure had in contrast with those avoiding sexual pleasure. Feeling comfortable in having sex outside a love relationship as well as in being paid for it renders these types of pleasure possible, while considering sexuality should be expressed only with lovers produces shame, disgust and much displeasure when doing the paid sexual performance.
\end{abstract}

Keywords: Femininity, Performance, Pleasure, Sex work, Skills 


\section{Introduction}

Offering oneself as a sexual object to be looked at and fantasized upon (as in erotic dancing) or offering sexual services for payment (as when offering escort services) irremediably brands women sex workers of the whore stigma. Within the last centuries in Occidental societies, such a behavior has been constructed as a sexual deviance on the part of the woman who would, thus, contravene the obligation made upon her to have sex only with her husband or - as this obligation opened up within the last decades - at least within a loving relationship with a committed partner. The whore stigma identifies the person as being despicable and losing all rights to be socially treated with respect since she "sells her honor by offering to hire her body for base gain or for an unworthy doing, specifically sexual intercourse" (Pheterson, 1993, p. 39). Being judged as bad, sex workers often get disrespectfully treated, both by intimates (Bradley, 2007) and by the society at large (Bruckert, \& Chabot, 2010; Pryen, 1999). Some sex workers manage to maintain a good self-esteem in spite of this (Bernstein, 2007; Downs, James, \& Cowan, 2006; Griffith, Mitchell, Hart, Adams, \& Gu, 2012). However, many internalize this social perception that they are being bad and despicable, suffer a consequent loss of self-esteem and have to struggle to still maintain some good self-esteem (Benoit \& Millar, 2001; Clouet, 2008; Orchard, Farr, Macphail, Wender \& Young, 2012; Pryen, 1999; Sanders, 2004b).

Despite the fact that sexuality is at the center of sex work and is the target of the whore stigma, few studies focus on the experience of sexuality and on its representations among the women who do offer sex for payment. However, a literature review (see Comte, 2010) makes it possible to identify the use of two different sets of strategies that specifically deal with the sexuality aspect of this type of work in order to diminish the impact of the whore stigma ${ }^{1}$. One of these sets of strategies, used by many sex workers, is to affirm their own good moral values through showing that if they are doing this type of work, it is only out of financial necessity but that they are having no sexual pleasure in doing this. To maintain this affirmation, they construct sexuality performed with the clients as being totally different from private sexuality with lovers, which they do by avoiding all sexual desire, sensations and pleasure as well as emotional sharing while being with the clients (Abel, 2011; Brewis \& Linstead, 2000; Messervier, 1999; Oerton \& Phoenix, 2001; Parent \& Bruckert, 2005; Sanders, 2002, 2004a, 2004b, 2005; Warr \& Pyett, 1999; Weatherall \& Priestley, 2001). At the same time, they reject the whore stigma upon sex workers who do get sexual pleasure in sex work encounters (Bruckert, 2002), and construct the clients as being those who are both immoral and weak since they can't control their sexual urges and spend money to get sexual release (Bruckert, 2002; Sanders, 2004a). They do, however, experience their performance of sexuality as work as being alienating and degrading (Brewis \& Linstead, 2000; Messervier, 1999; Parent \& Bruckert, 2005; Sanders, 2004b). Another set of strategies, used by other sex workers, is to question prevalent sexual norms and the consequent whore stigma branding of those who do not conform, considering sex work should never be seen as immoral or degrading whether for sex workers or for clients. They perceive sexuality as being something

Besides these strategies, another important one being used is to disclose the fact of personal involvement in the sex industry only to people who can accept and respect this, while keeping the secret to all others (Koken, 2012; Sanders, 2005) 
natural and healthy, making it worth the undertaking to both provide sexual services to clients and to personally experience the sexual pleasure that might come out of the activities thus performed and, as a result, they usually experience their performance of sexuality with clients as being empowering rather than degrading (Bell, 1995; Bernstein, 2007; Kontula, 2008; Parent \& Bruckert, 2005; Queen, 2002). Studying such a group of sex workers, Bernstein (2007) noted that they tend to embrace both an ethic of sexual experimentation and freedom for themselves and an ethic of authenticity towards the client which is both genuine and constrained within professional boundaries.

Therefore, while some sex workers avoid sexual pleasure when they perform sexuality with clients, others allow sexual pleasure to happen whenever the situation makes it possible. These observations point to experiences of sexuality within sex work that appear to be very different depending on how sex workers both perceive sexuality and deal with the whore stigma. However little is known about the personal emotional experience of sexuality that occurs when allowing or avoiding sexual pleasure within sex work as well as about the representations of sexuality that might be behind the choice of allowing or avoiding pleasure. Because of this lack of knowledge, most understanding of what this experience of sexuality might be is based on ideological constructs which either argument that sex work can only be destructive to the woman who is thus being abused and degraded by men's use of her body (Barry, 1995; Dworkin, 1993; Jeffreys, 1997, 2009; MacKinnon, 1985; Pateman, 1988) or, on the contrary, argument that sex work can be sexually empowering when done in rejection of social sexual norms and becomes a space where sex workers experiment sexuality, express themselves as sexual beings, and learn to gain control in the sexual encounter so that they are respected both as human and sexual beings (Bell, 1995; Califia, 1994; Queen, 1997; Willis, 1992). Hence, the aim of this study was to understand how the experience of sexuality constructs and organizes itself among women offering escort services, with the hope that this would help us identify the processes behind.

After reviewing methodology and presenting the sample, I will first discuss the experience of sex work performance through the skills that have been identified by participants as necessary for a good performance. I will then present two different emotion work processes that seem to be put into action according to two different set of perceptions of sexuality and of sex work, one fostering sexual pleasure acceptance and the other rather encouraging sexual pleasure avoidance. Following this, I will present the different types of pleasure that could be experienced by at least some of the participants, reporting the experience and perceptions of sexuality and of sex work of those who pursue or accept sexual pleasure and of those who avoid it. Finally, I will reach conclusion showing that different perceptions about sexuality and sex work bring different processes in dealing with pleasures that may occur while doing a paid performance of sexuality and that these different processes result in different experiences of sex work, which either produce feelings of personal satisfaction and self-accomplishment or produce feelings of shame and alienation. 


\section{Methodology}

\subsection{Interview content}

Two semi-directed interviews of about 90 minutes each were designed in order to explore both the emotional experience and the representations of sexuality of the participants. The first interview focused on the perception and experience of sexuality that the participants have while they do sex work, on one hand, and while they have sex in their private life, on the other hand. Participants were asked to describe what happens during an encounter with a client and what happens when with a lover or a spouse in their private life, to compare both experiences and to develop both on how they felt and on how they understand sexuality in each of these two situations. The second interview went deeper into the three aspects of sexuality $^{2}$ as identified in sexoanalysis (Crépault, 2007) ${ }^{3}$. I invited the participants to discuss how they experience and what they think about the desire for emotional intimacy as well as about the desire for genital stimulation and pleasure, whether it is in sex work or in private life; to discuss how they experience and express, or not, their feeling of femininity, whether in sex work or in private life; and to discuss the way they interact with men and with other women in their life in general.

\subsection{Data analysis procedure}

I used grounded theory methodology to analyze data, gradually developing categories along the way and being careful to remain as close as possible to what participants were telling me. In doing so, I was looking for categories that would best describe what was being there, and trying to identify possible relations between these categories. The interview with the seventh participant brought new data that allowed the emergence of an element of theory regarding pleasure from the performance of sexuality itself. After this new theme was identified, I returned to previous interviews and, in some of them, I recognized data corresponding with this new theme. Subsequent interviews also brought new data and helped develop an understanding of what types of pleasure, sexual and non sexual, can be experienced while doing sex work and of the conditions that encourage or hinder these types of pleasure. During this process, a validation of the developed categories has been done by two other researchers. As well, once the types of pleasure and their conditions for happening were identified, I returned to the participants in order to verify the theory in development. Those who answered said they fully recognized themselves in it.

These three aspects are: 1) the erotic function, which includes the desire for genital stimulation, the desire for emotional intimacy, and the sexual fantasy dynamics; 2) the gender identity, by which an individual defines oneself according to what he or she perceives as being a feminine or a masculine identity; and 3) the interaction with the other as a sexual being of the same sex or of the other sex. These three aspects are expressed in the perception one has about oneself and about others as people of one or of the other sex, as well as in sexual attitudes and behaviors. They are also related to the sexual representations one has developed through one's personal life experience.

While being professor in the department of sexology at l'Université du Québec à Montréal, Claude Crépault developed a sexological theory that could be used both for a general understanding of human sexuality and as a clinical approach. I used his definition of sexuality as it seemed helpful in order to explore more precisely the participants' representations and experience of sexuality. However, since I wanted to stay very close to what the participants were saying, I didn't use the sexoanalysis theory while developing categories, analyzing or interpreting data. 


\subsection{Sampling procedure}

After the approbation of my project by the university comity of ethics ${ }^{4}$, I contacted three community agencies offering their services to sex workers, two of whom have a clientele mainly composed of socio-economically vulnerable sex-workers and of people having alcohol or drug related difficulties, while a third one have a clientele composed both of socio-economically vulnerable and of much less vulnerable working-class and middle-class sex workers. I was able to meet some participants through these agencies. In accordance with snowball sampling technique, these participants were asked to talk about the research to their colleagues, some of whom then contacted me to offer their participation. Noting that I was only interviewing women who had the purpose of exploring sexuality as one of their main motivations to offer escort services, I proceeded for a theoretical sampling, through the already established contacts, in order to meet women escorts who were avoiding sexual sensations and pleasure while performing sexual services. This brought a few participants in this category. I also contacted escort agencies that advertise on Internet, but none of these answered back. As the interviews were progressing, I noted a third group of participants regarding sexual pleasure: these have no expectations regarding sexual exploration but will however accept sexual pleasure when it is present.

Anonymity and confidentiality of participants' testimony were a priority. When contacting the researcher, potential participants were given the choice to use their real identity or to only give their work nicknames, phone numbers and email addresses. After presenting the research and answering questions from participants, I took verbal consent at the beginning of the audio recording of the interview rather than asking participants to sign a consent form, in accordance with the CÉRUL's recommendations. Finally, when using data, names and places were changed and I took great care not to disclose any information that could identify them.

\subsection{Participants}

In order to be included in the study, potential participants had to be currently offering escort services or to have had offered them in the past, and they also had to be adult at the time of the interview. I met 16 participants from Montreal and Quebec city areas, in Canada, all being from working or middle classes and speaking French ${ }^{5}$. They were aged from 21 to 54 years old, for a mean age of 34 . When they first began within the sex industry, they were aged 13 to 45 years old, for a mean age of 24 . Three of them started when they were under 18 . Fourteen participants were either presently working as independents, or were working as such when they quit, and of these, ten previously had agency experience. At the time of the interview, three of them had quit the sex industry: two because their lover requested it and one because she preferred to put her energy toward university studies. Two participants were trying to quit sex work because they felt discomfort while performing sexual services but, at the same time, they felt a gain in self-esteem by the amount of money they made through sex work and this is what kept them from quitting ${ }^{6}$. Two other participants experienced discomfort and

Which is the Comité d'éthique de la recherche de l'Université Laval, CÉRUL.

For this reason, all the verbatim extracts presented in this article are translations from French to English.

Prices for a regular one-hour encounter ranged between $120 \$$ to $200 \$ C A$, while role playing calls commanded higher fees depending on what was requested by the client. Agencies' commission would usually be half the amount normally payed 
ambivalence while performing escort services. They wanted to continue as this allowed them to maintain their lifestyle, but if they could find another type of work that payed as much, they would rather change for one outside the sex industry. Finally, nine participants did not wish to quit sex work as they felt comfortable to offer escort services and appreciated both its revenue and the opportunity it offered to meet interesting people and to get sexual encounters that can be quite enjoyable.

The resulting sample mostly included women who felt comfortable both to offer sexual services and to talk about sexuality. The research procedure requested that participants discuss sexuality within two different interviews, and this probably discouraged most women who feel uncomfortable discussing their sexuality so intimately to participate. In fact, all the participants that felt uncomfortable about offering sexual services accepted to participate through the encouragement of an escort who already participated. As such, this study didn't reach data saturation as the last interviews conducted with women avoiding sexual pleasure were still giving new data.

Congruent with observations from earlier studies about sexuality in sex work, women from this study either enjoyed sexual pleasure arising from the encounter with the client or avoided such pleasure. A first group of women escorts were actively pursuing sexual pleasure through their professional encounters, most of whom seeing sex work as an interesting opportunity for sexual exploration (eight participants in this study). In order to do so, these tended to publicize their services as being centered towards a sharing of intimacy and mutual pleasure and subsequently chose, among potential clients, those who were more likely to bring them sexual pleasure. A second group accepted sexual pleasure when the situation made it possible but they did not actively pursue their own pleasure (three participants). A third group avoided most or all sexual sensations and pleasure (three participants). Women from these two last groups did not operate a choice among clients in terms of the sexual pleasure they might get but they did, however, reject clients who showed a disrespectful attitude, the exception being when the escort was in a vulnerable position and not able to recognize and impose her limits, such as of young age or when intoxicated. These three groups are not mutually exclusive, and two other participants were either accepting or avoiding sexual pleasure depending on the situation (avoiding sexual pleasure when they had a lover, or, even, accepting or avoiding sexual pleasure merely depending on the mood of the moment).

\section{Doing performance}

According to Goffman (1959), everyone, in their daily activities, necessarily presents a performance when interacting with others, through one's self presentation (physical characteristics, dress, demeanor) as well as through the actions one does in order to process the interaction in a way that gives the intended results. It follows that whatever the type of work, whether it is that of a medical doctor, clerk or garage mechanic, for example, one has to take on a specific routine encompassing both the type of self-presentation and the actions that fill the contract, and in doing so, performs the intended role as a specialist in the service

for a regular call; in return, they would take all costs in charge. Independent escorts kept all the money received for the service; however, they had to manage their enterprise and pay all the costs involved in doing so. Compared to this, minimum wage in the province of Quebec was around $10 \$$ an hour. 
to be provided. Just as in any other type of work, escort services also require a performance which encompasses both a self-presentation and a set of actions that fill the contract, these being the means through which clients get the service for which they paid. Furthermore, according to Goffman (p. 18), such a performance can be considered "sincere for individuals who believe in the impression fostered by their own performance", while it may be identified as "cynical when the individual has no belief in his own act and no ultimate concern with the beliefs of his audience".

When asked to describe what offering escort services meant for them, participants who either pursue or accept sexual pleasure explained that it meant rendering a fully professional service from which follows a revenue. Considering that sexuality is a natural physiological and emotional need that cannot always be fulfilled within a personal relationship, they saw their work as fulfilling a need which is very much present in society. As such, they saw themselves and their work as socially useful, and for $\mathrm{Candy}^{7}$, it went as far as being a vocation.

I have clients who are extremely shy and who don't have the capacity to go towards women of their age. [So, through a series of gradual steps, I help them to overcome their shyness.] I also have a client who is handicapped, [severely, and] for these people, it's often difficult to have a sexuality. [...] It's a service to society. And to men who need this... tenderness. [...] The client, he may be very handsome, but he is thirsty for tenderness because he does not have the time, sometimes, to have a girlfriend. He works too much. (Candy)

Offering sexual services means giving a moment of happiness that the person may not be able to get outside. (Heidi)

They believed in the work they do, invested their personal self and sexuality in the interaction with the client, and considered that their professional activities were personally rewarding in terms of self-actualization. Their aim, when they performed their work, was to answer their clients' sexual and emotional needs to the best they can, while respecting their personal capacities and limits and maintaining professional boundaries so that the service provider/client relationship remained healthy both for themselves and for the client ${ }^{8}$. As such, their performance would be considered sincere according to Goffman's criteria (1959). Studying middle-class women escorts, Bernstein (2007, p. 473) identified a similar process and used the term "bounded authenticity" to describe "an authentic, yet bounded, interpersonal connection" that these escorts put in place while being with their clients, observing that they embraced "an ethic of sexual experimentation and freedom" congruent with the values of "fun, pleasure and freedom" (Bernstein, op. cit., p. 477) held by middle-class people. Accordingly, these participants experienced different types of pleasure while doing their work.

All names have been changed for a fictitious one in order to maintain anonymity.

These boundaries allow for the limitation of the work activities to the period assigned to them. They also ensure that confusions between the status of client and that of friend will not happen, thus avoiding emotional and financial disappointments that may follow from the sliding of one type of relation to the other. 
On their side, participants who avoid sexual sensations answered that offering sexual services only meant "money" to be received. They took the role of escort while des-identifying with it, and didn't bother about the quality of their performance. They also avoided emotional contact with clients and didn't care about the clients' needs and feelings, sometimes even showing hate.

I've always been authentic in my life, but [...] when I was with a client, it was like it was not me. [...] I was taking [the role of] the girl who does... It was not me, in fact, because I was putting aside everything that is personal, everything that is moral value $[\ldots]$, because it was not something that I appreciated to do and I didn't want to invest myself personally in it. [When it's time to do the sexual act, often,] I rush, I just don't talk. That will go faster. He will do it faster. (Paola)

During the first years, [...] I didn't want to foster customer loyalty. I was telling myself: "If they come to see me once, they bring me money, and just too bad..." I preferred to get new people than to see these people come back and, above all, that they like the service I give them. Sometimes, I was shitty, I was real shitty because I didn't want them to come back [laugh]. (Oceane)

In my head, they're all assholes! I am really revolted against men. It's really for that that I do this. (Evelyn)

For these escorts, a good performance was one where they succeeded in hiding their disgust of the sexual acts they performed, and in making the client come quickly so that they could leave soon after. This, following Goffman's observations (1959), could be identified as a cynical performance. The process of des-identification from the sex worker role and of distancing from the work performance that these escorts used in order to protect their self-identity from the whore stigma and to maintain a meaning of sexuality as being exclusively an expression of love, has been discussed by different authors (Abel, 2011; Brewis \& Linstead, 2000; Messervier, 1999; Oerton \& Phoenix, 2001; Parent \& Bruckert, 2005; Sanders, 2002, 2004a, 2005; Warr \& Pyett, 1999; Weatherall \& Priestley, 2001). Such a process, because it creates a psychological distance from the work to be done and from the client, is opposite to the process of bounded authenticity identified by Bernstein (2007), which creates a sense of the self as being congruent with the job to be done while giving space for an emotional contact with the client. Differently from the participants pursuing or accepting pleasure, the participants avoiding pleasure experienced much more displeasure than pleasure both through the escort service performance and the sexual performance itself.

As this article is centered on the pleasures experienced within a paid performance of sexuality, the following sections will focus more on the experience described by the participants who either pursue or accept sexual pleasure. We will first examine along what lines escorts pursuing or accepting sexual pleasure realize a good work performance and what means they use to succeed in their task. Following this, we will see these types of pleasure in detail, as well as the sexual representations and sex work experience of both groups of participants. 


\section{Skills necessary for a good work performance as an escort}

Besides the general competencies that are useful in any job having to deal with clients, the participants pursuing or accepting sexual pleasure within their paid sexual performance identified three main qualities and competences which are necessary in order to fulfill successfully the escort service contract: first, an ability to present oneself as beautiful, feminine and sexy; second, listening skills, openness towards the client's needs and willingness to take care of those; and third, sexual competence.

\subsection{Self-presentation}

Regarding self-presentation as being beautiful, feminine and sexy, however, there seems to be no hard rule. Even though some participants asserted certain specificities as being essential, other participants were not corresponding to these and were still successful. Most participants, for example, said that it was imperative to use make-up when working, while one participant never used it and still was successful both as erotic dancer, masseuse and escort. Many participants thought it was necessary to be slim, but one participant had a fully round figure with $100 \mathrm{~kg}$ for a height of $1 \mathrm{~m} 65$ (220 lbs for a height of $5 \mathrm{ft} 5 \mathrm{in}$ ), and she claimed to be very popular and appreciated by her clients. Another participant was amazed to see that even though her body shape was that of a strong woman working on a farm rather than of a slim delicate woman, her clients found her beautiful. While young age is often associated with beauty, participants in their thirties, forties or even fifties seemed to receive just as many clients as women in their twenties. One participant asserted that long hair was essential to attract clients, but some other participants had very short hair and most of the others had shoulder length cuts. One participant assured that beautiful breasts (which she said she had) were a must, while another participant told that success lied not so much in breasts but rather in having a beautifully curved ass like hers... Moreover, as noted by some participants, a very ordinary beauty who is of a pleasant nature and is intelligent enough to be able to sustain a good conversation, will more easily maintain a good clientele than a gorgeous woman who is socio-culturally disadvantaged.

When asked to describe how do they have to show femininity when working as escorts, the concepts of beauty and femininity were partially entangled. In order to be beautiful, it is necessary to use make-up (or to be slim, have long hair, beautiful breasts, curved ass) but some of what is necessary in order to be feminine goes along the same lines (make-up, slenderness, long hair, etc)! Besides this, however, participants identified the use of "feminine clothing, made out of soft, molding, semi-transparent or lace-work fabric, for example, which would advantage the feminine curves of one's body as well suggest softness. High heels were also often mentioned as adding a feminine touch to the self-presentation. Finally, softness in the attitude, the gestures and the voice, as much as in the way one touches the client, was also almost unanimously cited as being a necessary feminine quality to have as escort.

Sexiness, for its part, relied on a self-presentation as being beautiful and feminine, while it more specifically referred to all the non-verbal cues (through demeanor, gestures, voice, face expression) and verbal approach to the client that foster the impression that the escort is interested in sex, enjoys it, and is willing to have sex with him. 
These observations indicate that women do not have to correspond to a specific set of beauty or femininity criteria to be successful as escorts and that men are not necessarily attracted to a youthful gorgeous looking body. At least some of them may rather be looking for an interesting woman who has personality and some culture and with whom they can relate on a personal level as well as on a sexual level. These results are different from those of Sanders (2004a), Trautner (2005) and Wesely (2003) who observed that their participants modeled their self-presentation as sex workers to a narrow set of stereotyped criteria of beauty and femininity in order to correspond to men's fantasies of the ideally beautiful and feminine woman and thus make money (blond, slim and with abundant breasts being the ideal of femininity, according to Trautner's and Wesely's studies). This difference in results might be explained by differences in sampling, as these authors studied sex workers from clubs and brothels while this study was mainly composed of independent sex workers. In clubs and brothels, the ideal might defined by the employer and/or by the club or brothel culture, these constructing what they believe men want and thus asking women working there to conform to these constructed expectations. As independent sex workers, participants could more easily remain themselves and attract the type of men who are interested in their own type of presentation, this accounting for the variety of self-presentations as beautiful and feminine that emerged from this study.

\subsection{Listening skills}

Besides self-presentation, participants noted that doing a good work performance needed from them that they be attentive to the client's needs, either by intuiting them through the non-verbal and verbal cues the client is giving or by asking him directly what he would like to experience. They stress the importance of good listening skills and of being empathetic, respectful and not prejudiced toward the client.

It's very necessary to listen attentively to the person. Be a chameleon and adapt oneself to what the other wants. We have to take care of the person, be caring towards him. [...] During one hour, [...] I try that the client feels good and that his needs are satisfied. He has sexual needs, but it's not only that. Clients [especially the older ones I receive] need to be touched. Their wife does not have sex with them anymore but she doesn't hold them in her arms either. (Beatrice)

Some participants added that they happily possessed the ability to be open to the person of the client and see the beauty in him even when he is not physically attractive, even when he is very old, in his 70's or 80's. Participants asserted that most of their clients want a good talk and not only sex, and many said that within the hour, the sexual activities take only 5 to 15 minutes. Clients need to talk about their life, their good deeds as well as the problems they are going through. Joane said that she often saw herself as a cheerleader encouraging clients to see life positively and Irina assured that owing to her listening skills, she prevented a client to commit suicide. Clients also want to exchange ideas about life, discuss subjects that are of actuality, or share about different life experiences (being a parent, a self-employed worker, or a tourist visiting another country, for example). This observation echoes one made from other studies (Bernstein, 2007; Clouet, 2008; Lucas, 2005; Jeffrey \& Macdonald, 2006; Lever \& 
Dolnick, 2010; Milrod \& Monto, 2012; Milrod \& Weitzer, 2012; Sanders, 2006, 2008; Welzer-Lang, Barbosa \& Mathieu, 1994) about clients looking for an encounter, if not a relationship when they become regulars, in which a warm interpersonal and emotional exchange accompanies the sexual encounter (Comte, 2015).

However, as some participants observed it, the encounter must be pleasant for the client. So, even though the escort will be asked to listen to the client's life difficulties, it is not a good idea that she talks about her own or that she complains about life; doing so will turn away the client. Irina gave the example of this regular client who called her for an appointment. When she talked about the problem she was going through at that moment, he told her to take care of herself and that he would call back later when her problem would be solved and she would feel better. In such a situation, clients who are not yet regular usually never call back. This is no different, as Oceane mentioned it, than in any other professional relationship where professionals start discussing their own problems; clients then feel cheated of their own hearing time.

\subsection{Sexual competence}

Sexual competence, that is to be able to intensify the sexual excitement of the client, to give him sexual pleasure and to finally bring him to orgasm, is another requirement in order to perform successfully as escort. Again, this aspect of sex work is not independent of the two others, as the escort needs to know how to present herself as beautiful, feminine and sexy, this being one way to arouse the client's desire. She also has to be able to listen to and/or intuit the clients' sexual needs and desires (his sexual dynamics), so that she can choose what approach she'll use to foster his pleasure. Furthermore, she has to be familiar with the masculine body and his reactions. As Maryse pointed it up, "men do not have the same sexuality, do not have the same way to see things that women have. [Recognizing this] can help to better understand the job and to do it better." The escort must know how to ignite the desire through a seduction approach, whether through voice, eyes, sensual gestures and touch. She must also possess a knowledge of the different techniques that can be used in order to arouse the excitement, foster pleasure and cause orgasm, whether through the physical stimulation of the client and, or, through a convincing demonstration of her pleasure whether real or simulated. Sexual competence can further be expressed through teaching clients about some practical aspects of sexuality, depending on their needs or shortcomings. For example, Candy made a specialty to receive clients who are too shy to meet women and thus never had sex. Through a series of steps that can take many emails exchanges and encounters, she taught them to approach a woman and feel secure in doing so and, once they feel all right, she introduced them to sexuality. Practicing bondage and domination in private life, she also taught security with clients she received for such sessions. Irina taught her clients to touch her and become good lovers as well as to explore different new sexual scenarios. And Joane taught some clients to learn to appreciate a sexual encounter that gave them the time to enjoy the sexual pleasure brought by an exchange of different sexual caresses and stimulations, which culminated in one orgasm, rather than looking for several quick releases in a one hour session. 
Sexual competence is barely described in other studies. Kontula (2008) mentioned that her participants, who mostly accepted sexual pleasure, did not seem to put much importance on sexual skills as compared to listening skills, as they explained that escorts soon know about the positions and sexual techniques needed for the work, while it is most important to create "just the right amount of intimate atmosphere for each client" (p. 612). Parent and Bruckert (2005), on their part, identified knowledge of the masculine body as well as sexual stimulation techniques and security knowledge in the case of bondage and domination sessions. Reporting about sex workers avoiding sexual pleasure, and thus having to fake sexual arousal, pleasure and orgasm, Sanders (2005, p. 330) noted that they tended to look at "pornographic films to learn to perform erotic acts. [...] Faking orgasms and sexual excitement is a female skill that is learned through sharing stories, imitation and dramatic performances." As such, these women tended to exaggerate signs of sexual excitement the way that it is done in the films, distancing themselves even more from a sexual performance that is meant to be very different from their real sexual responses as they consciously were differentiating sex at work from private sex. Contrasting with this observation, women of the present study who pursue or accept sexual pleasure, because they allowed themselves to identify with their self-presentation as a sexually aroused woman, were able to fake arousal and orgasms using their own habitual reactions.

\section{Comfort with sexual arousal while doing a paid performance of sexuality}

According to Hochschild (1983), jobs dealing with clients are ones of emotional labor as the self-presentation offered to clients requires a demonstration of an emotional state that will bring the intended emotional reaction from clients (for example, feeling warmly cared for). Escorts who avoid sexual pleasure do what Hochschild called surface acting in order to have this presentation, taking the role of a sexually aroused woman while absolutely feeling no such way. As it has been discussed in previous studies (Abel, 2011; Brewis \& Linstead, 2000; Messervier, 1999; Oerton \& Phoenix, 2001; Parent \& Bruckert, 2005; Sanders, 2002, 2004a, 2004b, 2005; Warr \& Pyett, 1999; Weatherall \& Priestley, 2001), these women do emotion work (Hochschild, op. cit.) within themselves, playing a role that is constructed as different from who they are, maintaining an emotional distance between themselves and clients, and emptying the sex they sell of all feeling - making it "clinical and sterile" (Sanders, 2005, p. 327 ) - so that it can constructed as different from the one they express in their private relationships, thus preserving the meaning of sexuality as expression of love. They do so in order to protect their self-identity and their self-esteem as this allows them to prove both to themselves and others that, in spite of their work, they remain women with morality.

On their side, escorts who accept sexual pleasure do what Hochschild (1983) identifies as deep acting. They work on their emotional state in such a way that they truly feel empathy for their clients as well as sexual arousal whenever the circumstances make it possible, creating a space of "bounded authenticity" (Bernstein, 2007). The emotion work they do is consequently of a very different nature from the emotion work done by escorts who avoid sexual pleasure. While the process of creating a space for empathy is the same as the one occurring in other types of personal services which imply some degree of psychological or physical intimacy, creating sexual arousal is specific to sex work. Being comfortable to experience sexual 
sensations and emotions outside a lover relationship as well as within a paid sexual performance, these participants are able to let their own arousal build up during the sexual interaction with the client, using whatever stimuli there is, whether it is from the client's appearance and personality or from the sexual interaction itself.

I had this kind of $[\ldots]$ casualness regarding sexuality. [...] It's funny because I think that when I woke up in the morning, I had the feeling, already, that I could foresee if everything would be fine, if I would be generous of my body or if I would instead be closed. And this would depend on the days. You know, a mind, a spirit, maybe more libertarian, that, yes, you are ready for... [...] But, as I tell you, regarding physical appearance, the age never really limited me. I have had orgasms with some grand-dads and not at all with some very beautiful young men [of my age]. (Dona)

For me, it's like intimacy to kiss somebody, and this starts me. I sense the smoothness of the lips and that turns me on. I love that a lot. (Anna)

When I feel that the other desires me, it's arousing. Wanting to give pleasure also stimulates me. When I feel that I give pleasure, also, that stimulates me. Like in the case of a fellatio, I feel that I give pleasure and that arouses me, I feel excited. All these contexts bring forth desire. (Candy)

Thus, whenever the encounter made this possible, they enjoyed sexual pleasure and once in a while reached orgasm, sometimes during penetration but, most of the times, during a cunnilingus offered by the client. Some women explained that taking time to sexually prepare themselves before work helped in this process.

I was reserving some time before in order to create a buffer zone between ordinary normal life and work. Even if it's only, when I prepare myself and take my shower, to think that I could be fun sexually this time. To make myself enthusiastic and even avoid masturbating during that day or the day before, so that I keep some appetite, some place for desire. (Joane)

However, it is not always possible to get sexually aroused as some clients have a need or a lack of ability that hinders this process. Also, when these escorts meet many clients in a single day, sexual appetite may have been calmed down especially when orgasm was achieved in a previous encounter, making it more difficult to get to an intense level of excitement and to reach orgasm again. These escorts nevertheless felt at ease to simulate sexual desire, pleasure and orgasm whenever it was necessary for the clients' satisfaction. For them, it was not a question of fooling the client.

How I felt? I felt kind to be careful enough to demonstrate that I had pleasure. I felt it was mindful on my part to demonstrate that this was all right, and to let him believe what he wanted to believe. (Dona)

Their intention, when simulating, was to play a role in such a way that the client truly gets his pleasure. Similarly to these participants, Kontula (2008) also observed that even though some 
sex workers value their own sexual pleasure when they perform sex with clients, they do not require it to happen in order to feel good. Creating a space of bounded authenticity where they can remain themselves while offering sexual services, participants who pursue or accept sexual pleasure are then able to experience different types of pleasure, which are both of sexual and non-sexual. We will see these pleasures as they are experienced by those participants and as they translate among those who avoid sexual pleasure, comparing representations about sexuality each group holds and then presenting the two different processes implied in fostering or hindering those pleasures.

\section{Types of pleasures experienced in a paid performance of sexuality}

Three categories of pleasure can be identified through the discourses of women pursuing or accepting sexual pleasure when with a client. These are the pleasure resulting from work that is well done and leaves the client happy and satisfied, the pleasure resulting from performing sexually and, finally, sexual pleasure itself. Compared to this, women who avoid sexual pleasure expressed feeling some pleasure from receiving money for the work they did but not from the quality of the work performance itself, and they also expressed feeling pleasure from being recognized beautiful and feminine by their clients, this constituting a part of the sexual performance. Besides this, they mostly experienced displeasure, disgust, shame and alienation from their work performance. Goffman $(1959$, p. 18) noted:

It should be understood that the cynic, with all this professional disinvolvement, may obtain unprofessional pleasures from his masquerade, experiencing a kind of gleeful spiritual aggression from the fact he can toy at will with something his audience must take seriously.

However, while interviewing participants who mostly faked sexual arousal and pleasure, I didn't think about verifying if some of them did experience this type of pleasure in conning clients, and none of them spontaneously talked about this. So, even though this is a possibility for at least some of them, data from this study can neither say so nor say otherwise. Figure 1 presents both the types of pleasures experienced or not by each group and the processes behind these experiences.

\subsection{Pleasure resulting from work well done}

The pleasure felt towards one's own work that has been well done is a kind of personal satisfaction that can be experienced in any kind of good work performance and, here, it is most similar to the one experienced in clerical or professional work implying client service. Participants who pursue or accept sexual pleasure chose this type of work because they enjoyed sex, and believed it is an important part of normal human life, emotionally nourishing as well as physically relaxing and soothing. They questioned social norms about women's sexuality and, even though they might see sex inside a lover's relationship as especially wonderful, they also enjoyed sex outside such a relationship as they knew by experience that sexuality does not need to always be expressed within a lover's relationship, to be pleasing, nourishing and fulfilling. 


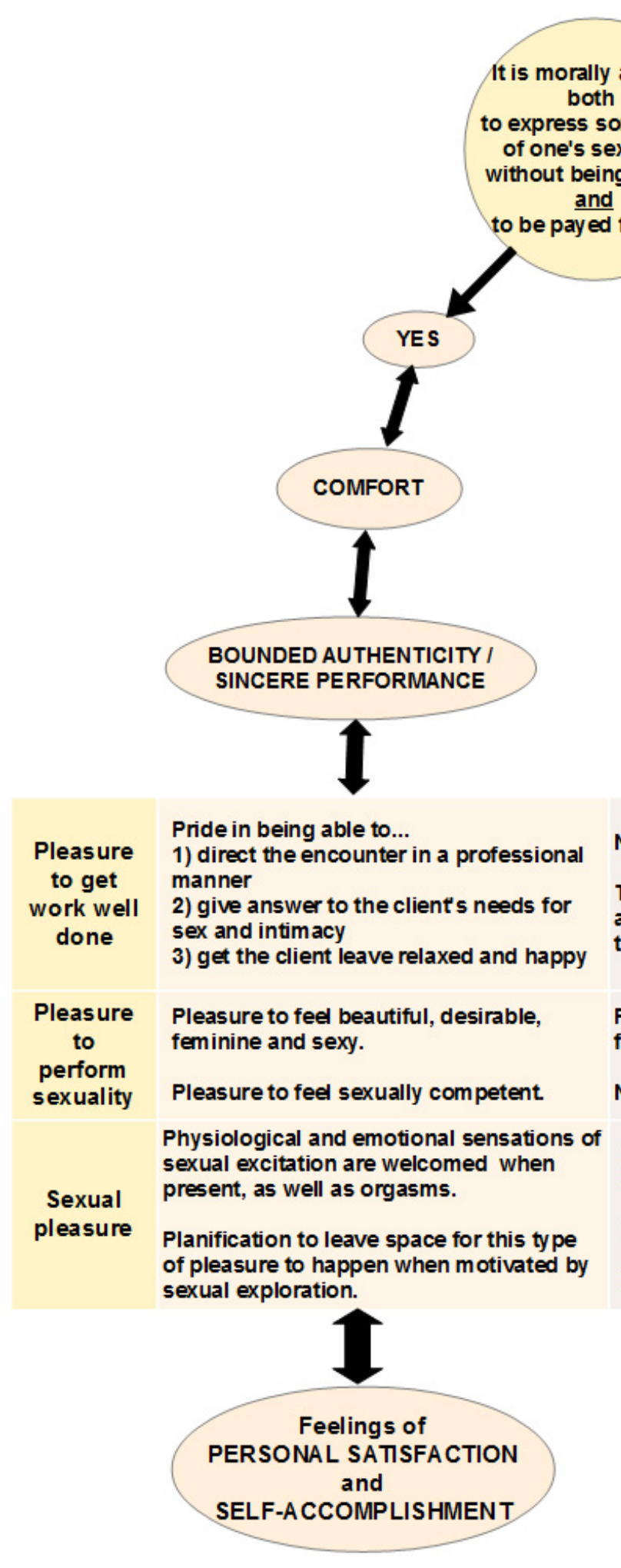

Figure 1. Types of pleasure that can be present or not during a paid performance of sexuality 


\section{Macrothink

I think that it would be beneficial for women that they put the emotional need aside a little bit, and learn to discover themselves without guilt. Because it seems that if women don't do it only for the physical, it's because they feel guilty to do it when it's just physical. It's also a little bit the reason why women cheat less than men. They will more easily feel guilty, while men make such an easy detachment. [...] We don't have to feel guilty to experience [sexual] pleasure, as long as it's healthy, and consensual, and safe. [...] I think it's part of this guilty feeling, [...] the fact that women do not have sex with lots of men. (Candy)

Interestingly enough, most participants of this group were either in an open couple relationship or were single, and many considered themselves bisexual, this observation being similar with that of Bernstein (2007) who also noted that many middle-class escorts valued sexual exploration and freedom in their personal as well as in their work life. From this point of view about sexuality follows the idea that people who feel the need for some sexual proximity with another human being should have access to it and professional sexual services are one legitimate way to fulfill one's own needs when it does not seem possible to have sex within a lover's relationship or, else, when having a lover's relationship just seems too complicated. These participants considered the sexual services they offered as being similar to other professional services and, feeling at ease with sexuality as well as appreciating personal contacts with people, they enjoyed their role as a sexual service provider and did feel pleasure in the process of pleasing the client, fulfilling his needs as well as helping him when he was in emotional or sexual difficulty.

I love to give the best service possible, it's that simple. I want the person to be satisfied when leaving, and this gives me some personal satisfaction, also. That seems nicely altruistic when I talk about it, but no, it's very selfish also. [This work] really develops my capacity to quickly create connections with people, and this is useful. Also, concerning sexual exploration, each sexual encounter is completely unique. [...] Each time, it's a new challenge. It's stimulating because it's a case by case approach. It's the ultimate in custom-made. (Gaelle)

When I see their smile... They leave and say: "Thank you very much, see you soon." To know that the client leaves and he is satisfied, that gives me pleasure. (Anna)

What I love the most [in my work] is to take care of the other person. It's to make from his experience something memorable. When the client gets sexual pleasure as never before in his life, and says "Oh, my god, that was so good!" [...], when he thanks me, when I see him happy when he leaves and says "I feel so light", when he writes back to me once at home "That was really good, I look forward to see you soon", that makes me vibrate. I feel that I did something good for somebody. Because, for me, being escort is a service that I offer, the same way as for a message. [...] It's to make somebody feel good. I realized [this] when I had my first encounters with very old people. At first, I thought "Well, I won't have any fun, that won't be great [tone without enthusiasm]", when I learned that the 


\section{Macrothink

gentleman was 82 years old. [...] In the beginning, I felt really disorientated, but afterwards, came a wave of empathy... I had, for an hour, to do some good to this gentleman, who is 82 yrs old and who probably hasn't been touched by his wife for the past 40 years... [...] So I was his little entertainment and I had to do my job well. It's sure that I was not super at ease, [...] it's obvious that the body of a 82 years old man, $[\ldots]$ we cannot undertake it the same way, we cannot do the same things, and it's normal. I did not really know how to do, but I tackled it well. [...] This is when I realized that my work was to make people feel good, and when I realized that in my work, I was making people feel good! I felt so good [and super pleased with myself] after that client. (Noemi)

Finally, many of these participants noted that through their experience as escort, they learned to develop businesswoman and professional skills, deciding on the work schedules, fees and meeting places where to give the service (personal home, hotel, motel, apartment reserved for work, or client's home), choosing what type of service they want to sell (girlfriend experience, courtesan, fantasy role play and/or porn star experience), identifying the type of clientele they want, advertising in printed media or web sites, selecting clients in order to avoid those that may bring problems, intuiting the client's character and needs so that they can tailor their approach to each client, handling adequately the situation when clients are talking or behaving inappropriately, keeping the exchange within the professional limits of bounded intimacy and, finally, conducting the whole encounter so that everything falls into place and that the client has the time, within the period he paid for, both to receive the emotional and/or sexual attention he is looking for without being rushed to finish or to get dressed because time is up. Joane, for example, mentioned how important it was for her to conduct the encounter so that there was time after sex to cuddle and complete the session on a tenderness note, hence giving enough time for the client to slowly come back to daily life reality. Participants gained self-confidence through the acquisition of these skills and talked about proud and pleased with themselves they feel to see that they can professionally manage the encounter so that everything works fine, recognizing that these skills are an asset for any worker having to deal regularly with clients on an intimate basis.

This pleasure regarding work well done, resulting from the personal acknowledgment that they were skillful and professional in their job and that they truly made their clients happier by helping them have some needs fulfilled, has been identified by the great majority of participants as being one aspect of their work that make them appreciate what they do. However, participants who avoid sexual pleasure rarely or never experienced this type of pleasure. Their representations of sexuality, clients and sex workers are different from those who pursue or accept sexual pleasure, involving a different process in the way work performance is done. Similarly to other studies' findings (Bruckert, 2002; Oerton \& Phoenix, 2001; Sanders, 2004a; Weatherall \& Priestley, 2001), these participants considered that sexuality should happen only within a monogamous love relationship, while they believed that most men are unable to remain faithful because they "can't keep their cock in their pants [and] want to screw all women they meet" (Evelyn). Also perceiving sex work as a social necessity but from a very different angle, they argue that it is better that men pay for sex than 
perpetuate sexual aggressions on women, and this is why, needing a job, these participants offered these services. As sex workers, they might feel pride in receiving money but they also felt shame in compromising themselves into doing sexual acts for that money. Having internalized the whore stigma, they saw themselves as not being normal and respectable. Considering that "women with good values don't do that" (Paola), they questioned themselves about their value as a person and as a woman: "What am I doing here? This is not normal! I am not a normal, respectable woman!" (Evelyn). This internalized stigma can be so strong that, in her first years as escort, Oceane had the impression that it was written on her forehead that she was a whore and until she questioned this belief, she would avoid social gatherings because of shame. Torn between the need to make money and the self-perception of not being normal, these participants then explained that it was not them who did the sexual service, it was the escort they were playing the role of who did it. Remaining uncomfortable while with the client as they felt disgusted of having to perform sexual acts for him in order to get money, they limited the sexual interaction as much as they could, and avoided to emotionally connect with him. Distancing from the performance they had to do and from the client, they had no wish to satisfy the client's needs and they tended to hurry up completing the task so that they could leave the client - and the bad moment they were going through - as soon as possible thereafter. Conflicts then arose with clients who wanted something the escort did not want to do (for example, kissing, having her breasts touched, receiving a cunnilingus or, even, penetration on first encounter as this was the case with Paola) which made the moment even more difficult to go through. Aware that clients wouldn't come back if they felt rushed or uncared for, some of these escorts made some effort to not appear rushing and they pretended to listen to him when that appeared necessary, confiding to the interviewer that, in reality, they didn't give a damn about the client and his problems. The whole encounter, both in its sexual and emotional aspects, therefore became a source of painful stress and displeasure for these participants.

\subsection{Pleasure resulting from performing sexuality}

While pleasure regarding work well done can be found in most jobs, pleasure felt while performing sexuality is specific to sex work. As we saw it earlier, a good sexual performance requires both a self-presentation as being beautiful, feminine and sexy, and sexual competence. All participants felt very pleasurable their performance of presenting themselves as beautiful, feminine and sexy, even among those who did avoid sexual pleasure, as this allowed them to regularly receive compliments from their clients, confirming that they were, indeed, beautiful and desirable. Participants who already felt beautiful and feminine before starting sex work found that performing femininity pleasurably nourished and reinforced their feeling of being feminine and desirable. For their part, participants who previously had doubts about their capacity to be beautiful and feminine found that doing sex work helped them to reconcile themselves with their body and to appreciate it more, recognizing that they could, indeed, be appreciated for their beauty and femininity (among other qualities), even if their body didn't correspond to what they learned to be the ideal of femininity.

To wear very feminine outfit, to see me in the mirror, to appreciate the image I was seeing, to feel more and more feminine through men's eyes who found me beautiful, 
attractive, gentle, sensual, that brought back this [feminine] part of me [that I had, and I cultivated it, and I loved it]. (Candy)

I loved it so much to prepare myself. I was doing it more for me, as it was important for me to have class. Once the dress removed, I wanted to have beautiful underwear. [After I stopped sex work], I missed to make myself beautiful. To prepare myself in order to be told that I was beautiful. To smoke a cigarette while I was putting eyeliner on. That was a ritual. I was always beginning the same way... And I was enjoying it a lot. (Dona)

[Offering escort services brought me to become] even more proud to be a woman. I feel stronger. So I accept even more my femininity. [...] I discovered my woman's body more and more, and that makes me feel feminine to be able to experience my sexuality... [long silence] I realize that I find myself beautiful... [joyful laughs] It's as if I reached a point where I am really pleased with myself... (Anna)

Femininity was also expressed through a play of seduction with clients, using both non-verbal gestures and verbal messages to convey the idea that both are interested in each other sexually. This seduction play is very important in erotic dance and all participants who also worked in clubs found this to be very pleasurable whether, as escorts, they accepted or avoided sexual pleasure.

When I started [erotic dancing], that was to learn how to seduce a man, how to move. [...] How to do make-up, wear high heels, wear sexy clothes, do hip and shoulder movements when you dance for somebody. Seduction dance, in fact, that's real art. It's the way you move, how you wink lightly at a client, how you approach him, how you talk to him, how you show him your breasts while bending down. [...] I loved very much to seduce, I took great pleasure to see that I was attractive. (Anna)

[In erotic dancing,] you see men's desire in their eyes, you see that it sparkles, you see that you attract their attention, you see that you charm. [...] You can't just say "Hello, do you want a dance?" It's sure he won't make you dance. You have to come and say "Hello, how are you? How was your day?" You work and you see it progressing. (Heidi)

Within the escort service, this play is useful for a good sex work performance as it creates an opening for the intimacy that will come and it nourishes the client's desire. But, outside this consideration, participants who pursue or accept sexual pleasure said that they did really enjoy this seduction interaction with clients both because it made them feel desirable and it nourished their own sexual arousal. Some also noted that this seduction play with clients had improved their ability to play it and have fun doing it in private life.

Discussion, as such, is some part of the seduction process. We look at each other in the eyes. We can brush lightly against each other. It's in all these little gestures of sensuality that we develop a little bit the excitation. [...] There is a pleasure to discover somebody. [...] It's from the moment I started to have relationships with 
men, that I had this desire for seduction and to learn to know the other. When you are in a monogamous context, you don't anymore have the right to do it. [...] But now [that I am in an open couple relationship], I can do it daily and it's very pleasurable. (Candy)

For the participants who avoid sexual pleasure, seduction play with clients as erotic dancers felt good as it confirmed they were desirable while the club's rules protected them from having to go through the sexual act itself. However, in the frame of escort services, this seduction play became part of the escort role from which they had to dissociate in order to protect their self-identity. Seduction play was no more interesting, then, as it was part of the role they found disgusting. In sum, they still enjoyed the compliments about their beauty and femininity, but besides the money they received, that was all they could enjoy from offering escort services.

Participants who pursue or accept sexual pleasure talked about the pleasure they felt doing the sexual performance as they saw the client get sexually aroused, express pleasure and finally reach orgasm due to their sexual attention and expertise. Developing this sexual competence was a cause of much pride for them.

This is a work that I do, so it's not without efforts. It's not true that it comes like that [Snap of the fingers]. But with the experience I get, ultimately, this becomes easy. [...] So, it's sure that this success is a pride for me. I am conscious that I am good in bed. [...] I worked hard for it. And how did I work hard to become good in bed, well, it's only in being very attentive to the partner, in being very open to his commentaries, to his reactions. [...], in being very alert and not in a bubble. All the movements, breathings, words that are prononced, ways of moving, the hand that clings to the pillow, these can be easy to figure out when it's overdone, when it's real, when it's reserve... So, it's really to be alert and to develop a capacity to understand clients' needs. And when we don't succeed in understanding them, well, it's to have the courage and the strength to ask [...] "Excuse me, I don't understand what you want me to do. Tell me, explain how you want me to do it and I will do it." [...] I learn from this, so it's to my advantage. (Noemi)

These participants enjoyed the opportunity to meet a great variety of people of different ages, of different ethnic groups, and expressing different needs, preferences, sexual fantasies and ways of getting aroused and reaching orgasm. Many of them underlined the fact that if it had not been of sex work they would never have met so many different people, never have developed such a richness of sexual experience and knowledge which revealed itself to be useful in their private lives. They discussed about the openness about sexuality this experience brought, the greater ease they acquired regarding nudity, sexual acts and sexual pleasure expressiveness, the non-judgmental attitude they developed about different ways of expressing sexuality and about sexual fantasies that they were seeing as strange or pervert before, the deconstruction of guilt about having sex outside a monogamous relationship and with so many men. Furthermore, doing sex as work and wishing to sexually satisfy the client, 
they learned to read the non-verbal of their clients during the sexual performance so that they could adjust what they were doing in order to reach their goal and this became useful thereafter with their love partners as they were more attentive to them when they were giving them some sexual attention. Finally, some of them also added that this great variety of encounters helped them to better know and understand - in a compassionate way - men's emotional and sexual needs, as well as men's ways of enjoying sexuality and of understanding relationships with women. Remaining themselves during the paid sexual performance, they could integrate as personal knowledge the acquisition of experience they were making there and thereafter use it in their private lives, enriching their sex lives with lovers.

Participants who avoid sexual pleasure rather expressed disgust in the sexual performance itself, thus dissociating themselves from the sexual performance. They mainly talked about how their experience of sex work brought them to become suspicious of men, being now afraid their lover would cheat them with other women (even when lovers didn't know about the participants' activities). Some of them also discussed how it remains difficult for them to completely keep memories of what they do with clients outside their couple's bedroom, these memories bringing back guilt and disgust when they pop up during sex with their lover. Far from being an opening experience towards sexuality, sex work became a traumatic experience for them, leaving them more vulnerable to relationship and sexual difficulties.

\subsection{Sexual pleasure}

Sexual pleasure, as such, is different from the pleasure felt from feeling beautiful and desirable or from having a man getting sexual pleasure and orgasm from one's own sexual attention. It is the physical and emotional pleasure felt from the increase of sexual excitation that happens in the body, this last bringing also a desire for sexual physical stimulation in order to nourish and create more sexual pleasure. Sexual pleasure is more than mere orgasm as it includes all the pleasure that comes from the sexual desire itself as well as from giving or receiving enjoyable physical sexual stimulation (Desjardins, 1986).

Women who pursue or accept sexual pleasure considered that taking the sexual pleasure which arises during a sex work encounter is both a positive way to do sex work and an interesting benefit from this type of work. However, as many participants noted it, sexual pleasure within a paid encounter must not be expected as, otherwise, the woman is bound to experience frustration part of the time. The good attitude, they said, is to be ready to take the sexual pleasure and the orgasm when they show up without nevertheless expecting them to happen. Some of these participants explained how the arousal seems to come naturally from within themselves, sexual desire arising easily through the establishment of an empathetic contact with the client as they focus on something they like in the client. After this, the sexual excitation and accompanying pleasure felt by the escort is nourished by the sexual interaction both through the arousal and pleasure expressed by the client and by the sexual stimulation received from the client, when there is some. These escorts also explained that the sexual desire they felt with the client was rather a desire for sexual stimulation than a sexual desire for the client himself; that, in fact, a strong desire for the client impaired their capacity to 
remain professional as they became self-conscious of what they were doing due to a desire to favorably impress the client. Some participants noted that the sex work situation helped them to explore and discover their body and their sexuality as, differently from the lover's relationship, they were not afraid of the negative reactions of the partner if they didn't meet his expectations. For example, until she became escort, Anna could not reach orgasm because she had always stayed within a tenderness range with her lovers. In escorting, she accepted to go into the intensity of sexuality and this is when she finally experienced orgasm. Joane got vaginal orgasms, which she usually doesn't get with her lovers, in situations with clients that she never thought would even excite her. Candy, for her part, experienced her first clitoris orgasm when she received a masturbation from a client.

I discovered that it was doing me good to let myself go with people who are not necessarily in my personal life. It seems that this was giving the possibility to not think about: "Will this going to take time or not before I get my orgasm?" Because it was always this that stressed me with the clitoris orgasm. It was taking time in my personal life. And I was telling myself: "My god, he's gonna find that long". But, [with a client that I liked, I told] myself: "I'm gonna just experience what he is giving me and if I don't get it, that won't matter". And that's when I got the key to get an orgasm. It helped to think to turn off the machine and just [let go]. (Candy)

On the other side, when I asked escorts who avoid sexual pleasure what they thought about sexual pleasure, they said that it is just not normal to have pleasure with a client. However, some of these participants sometimes got orgasms with clients, and this brought discomfort toward the client and guilt about themselves as they questioned their normality and moral value. Before she started to see escort services as a legitimate enterprise and accept sexual pleasure, Oceane would become angry when she would get an orgasm.

[Sometimes, the client] would make me get an orgasm and I was very much angry inside of me, because I was thinking: " Christ that I don't like that guy." I would have met this guy on the street and I would have never felt any desire for him. He would not have attracted me. But because I was more disposed or because he had a good touch, I had an orgasm. I was angry about myself. [...] I didn't want, maybe, to give myself this right for pleasure. Now, I learned to be a little more open to it, to accept it more. (Oceane)

Most of these participants explained that if they were allowing themselves to get sexual pleasure from clients, this would make them want more and more of it and they would no more be able to content themselves within a monogamous couple relationship, meaning that they would never be a normal respectable woman anymore. Or else, according to Lisa, one would become frustrated as one's desire would become too great and clients would not be able to fulfill these constantly growing needs.

As we saw, participants who pursue or accept sexual pleasure usually also found pleasure in the performance of sexuality both through self-presentation and sexual competence, while participants who avoid sexual pleasure only found pleasure in performing beauty and femininity but not in showing sexual competence. Besides this, from data emerged another 
possibility, that is of feeling pleasure in performing sexuality both in presenting oneself as beautiful and feminine and in being sexually competent while, at the same time, having no sexual pleasure.

\subsection{Performing sexuality with a type of pleasure that is without sexual pleasure}

All along her interview, Heidi was assuring that she was experiencing pleasure while doing erotic dancing and escort services and that it made her feel sexually accomplished. While I thought at first that she was talking about sexual pleasure, it gradually became clear that Heidi's pleasure was not sexual. Her pleasure came both from feeling desired and from her success in exciting the client and giving him sexual pleasure, which in return made her be recognized as sexually competent through the client's appraisal. Comparing sex work and private relationships, she stressed the fact that she received so many compliments from clients and that she very much enjoyed these compliments while in private relationships, she was rarely receiving them and just felt taken for granted. Finally, it was through this recognition from clients about her being desirable and sexually competent that she felt sexually accomplished. However, she didn't seem to experience sexual pleasure itself, and orgasm was very rare.

I don't experience it emotionally. [...] I fulfill the side that is expected from me as escort, to kiss and give a girlfriend experience [...]. So I experience sexuality at that moment more like criteria to accomplish, and once I accomplished these criteria, well, I succeeded in doing well my work and I am pleased with myself. [...] What I like a lot at this moment, is that I don't see the same guys, so this suits me even more. They see me once so I give the best. Because seeing them again, my sexuality would be different with them. [...] That would still be in the role. The only thing that would change would be the way I have to seduce [with] dresses, hairstyle, make up, music, wine or whatever. I would try to do something different. (Heidi)

Going back to previous interviews, I then observed that participants who usually get sexual pleasure sometimes experienced situations where the sexual pleasure was not possible and that this was fine for them as they nevertheless were pleased with the encounter. They felt pleasure in seeing their work as well done because it answered some of the client's needs, felt pleasure in feeling sexually desirable and, finally, felt pleasure in being able to bring the client to experience sexual pleasure and orgasm through their good mastering of sexual skills.

When I am with a client, I consider that I am there for him. And it's crazy but that will be one of the rare moments in my life where I won't find that a sexual relation is unsatisfying if I take zero pleasure, physically. [As long as] the client leaves satisfied and glowing, for me, that's gonna be a 10 on 10. That doesn't bother me to take [sexual pleasure] when there is some to take, but my vision of if it has been a successful encounter or not, that won't be dependent on if I got pleasure or not. (Gaelle)

Recognizing this difference between pleasure from performing sexuality and sexual pleasure 
per se allowed the identification of these different types of pleasure that many participants do experience while offering escort services. And this also explained how participants who pursue or accept sexual pleasure could still find pleasure in a sexual activity with a client that didn't bring them sexual pleasure.

\section{Conclusion: Remaining authentic versus distancing from the role}

While some previous studies noted the pride and personal satisfaction that some sex workers feel about their work (Bradley, 2007; Bruckert, 2002; Kontula, 2008; Lucas, 2005; Parent \& Bruckert, 2005) and reported that some sex workers would experience sexual pleasure in their work (Brewis \& Lindstead, 2000, Kontula, 2008; Parent \& Bruckert, 2005; Sanders, 2002; Warr \& Pyett, 1999), pleasure experienced while offering sexual services had not been explored before this study, with the notable exception of the work of Kontula (2008) about sexual pleasure. Pleasure about work well done was barely mentioned (Bernstein, 2007; Lucas, 2005). The performance of femininity and sexual competence has rather been presented as a necessity to conform to stereotypes in order to succeed as a sex worker (Sanders, 2005; Trautner, 2005; Wesely, 2003) and the pleasure dimension of both of these performances went unidentified, most likely because of samples where most participants distanced themselves from their work. Previous studies had also theorized about the separation process of the sex worker's identity from personal identity and of the work sex from the intimate sex, concluding that this process was necessary in order to protect the sex worker's self-identity as well as her personal sex life (Abel, 2011; Brewis \& Linstead, 2000; Oerton \& Phoenix, 2001; Parent \& Bruckert, 2005; Sanders, 2002, 2004a, 2004b, 2005; Warr \& Pyett, 1999; Weatherall \& Priestley, 2001). Because this study mainly attracted women who were at ease with paid performances of sexuality and felt comfortable discussing their own experience of sexuality, it brought into light another process where the sex worker remains herself and engages her own sexuality while performing escort services. This process had previously been identified by Bernstein (2007); however, this study went deeper into how this process comes into play, helping to understand both processes and their results on the women's experience of self towards sex work.

It appears that the choice of remaining oneself or of distancing from the role during a paid performance of sexuality depends on different sets of representations about sexuality and sex work. Viewing sexuality as something that can happily be experienced outside a committed relationship as well as during a performance with a client opens the possibility for the woman sex worker to feel comfortable in her role as a provider of sexual services. Believing in the wellness her escort services can bring to clients, she aims to truly give the service that she is offering. From this posture, she can remain herself and establish an empathetic contact with the client, which creates a space of bounded authenticity where she can take care of some of the client's sexual and emotional needs, while maintaining the relationship professional. Her performance remains sincere as she does feel that she cares for the client and believes that her performance does succeed in answering some of the client's needs. Putting part of herself and of her own sexuality into her performance, she can then feel pride in her qualities and skills as a good worker, as well as personal gratification in the results she gets. This, in return, 
fosters the possibility to experience different types of pleasure as well as a sense of personal satisfaction and self-accomplishment.

On the other side, viewing sexuality as being normal and moral only when expressed in a lover's relationship or, at least, when done out of desire and without being paid for it, brings the woman sex worker to separate work sex from private sex, emptying work sex of all sexual sensations that can be experienced in private sex. But work sex demands to show oneself as feeling sexual and to perform sexual acts while those are considered shameful when done for payment, so there is discomfort and even disgust in doing them. The whole encounter with the client becomes cynical in the sense that the sex worker does not believe in her performance and does not care about other results than the revenue she can get from it. She may find some pleasure from being recognized as beautiful and feminine but she can't allow herself to truly feel sexual (instead of only pretending she is) and to let sexual arousal and pleasure to take place within her. Even though she may feel proud that she can pay her bills because she works, her whole work experience becomes one of shame as she worries about still being a respectable and normal woman in spite of this work. It also becomes one of alienation as she has to do, for revenue, something she can't identify with and believe in, and this estranges her of a part of her life experience, thus causing her to experience a loss of identity. Even though distancing oneself from sex work performance can be considered a useful defense mechanism in order to protect one's self-identity and private sex life - as some previous studies theorized it - it appears to be so only in a situation when representations of sexuality demand to do so, since this process helps in protecting oneself from greater emotional damage. However this process still appears to be damaging compared to another possible process where one remains oneself following a different view of sexuality and sex work.

These results lead to the conclusion that women who internalize the whore stigma experience discomfort, shame and alienation as sex workers, while women who question and reject this whore stigma and the obligation made upon women to confine their sexuality inside a couple relationship are able to positively experience sex work. As such, this study opens to the possibility that doing sex work may not necessarily, in itself, be posing risks to emotional health contrary to what has been stated previously by other authors such as Abel (2011), Brewis and Linstead (2000) and Sanders (2004b, 2005), it is rather the internalization of the whore stigma that poses these risks.

\section{Acknowledgement}

The research has been financed by a scolarship from Fond de Recherche du Québec, Société et Culture (FRQSC) and by a doctorate degree student grant from Université Laval.

\section{References}

Abel, G. M. (2011). Different stage, different performance: The protective strategy of role play on emotional health in sex work. Social Science \& Medicine, 72, 1177-1184. http://dx.doi.org/10.1016/j.socscimed.2011.01.021

Barry, K. (1995). The prostitution of sexuality. New York: New York University Press. 
Bell, S. (1995). Whore carnival. New York: Autonomedia.

Benoit, C. \& Millar, A. (2001). Dispelling myths and understanding realities: Working conditions, health status, and exiting experiences of sex workers. Victoria: Prostitutes Empowerment, Education and Resource Society (PEERS).

Bernstein, E. (2007). Sex work for the middle classes. Sexualities, 10(4), 473-488. http://dx.doi.org/10.1177/1363460707080984

Bradley, M. S. (2007). Girlfriends, wives, and strippers: Managing stigma in exotic dancer romantic relationships. Deviant Behavior, 28(4), 379-406. http://dx.doi.org/10.1080/01639620701233308

Brewis, J. \& Linstead, S. (2000). The worst thing is the screwing (1): Consumption and the management of identity in sex work. Gender, Work And Organisation, 7(2), 84-97. http://dx.doi.org/10.1111/1468-0432.00096

Bruckert, C. (2002). Taking it off. Putting it on. Women in the strip trade. Toronto: Women's Press.

Bruckert, C., \& CHABOT, F. (2010). Challenges: Ottawa area sex workers speak out. Ottawa: POWER.

Califia, P. (1994). Whoring in Utopia. In Califia, P. (Ed.), Public sex. The culture of radical sex (pp. 242-248). Pittsburg \& San Francisco: Cleis Press.

Clouet, E. (2008). La prostitution étudiante à l'heure des nouvelles technologies de communication. Paris : Max Milo Éditions.

Comte, J. (2010). Stigmatisation du travail du sexe et identité des travailleurs et travailleuses du sexe. Déviance et Société, 34(3), 425-446. http://dx.doi.org/10.3917/ds.343.0425

Comte, J. (2015). Les clients des services d'escorte tels que perçus par des femmes offrant ces services. Revue canadienne des études supérieures en sociologie et criminologie, 4(1), 27-41. http://dx.doi.org/10.15353/cgjsc-rcessc.v4i1.121

Crépault, C. (2007 [1997]). La sexoanalyse. Paris : Payot. Collection petite bibliothèque.

Desjardins, J.-Y. (1986). L'approche sexo-corporelle, fondements théoriques et champs d'application. Psychothérapies, 6(1), 51-58.

Downs, D. M., James, S., \& Cowan, G. (2006). Body objectification, self-esteem, and relationship satisfaction: A comparison of exotic dancers and college women. Sex Roles, 54, 545-752. http://dx.doi.org/10.1007/s11199-006-9042-y

Dworkin, A. (1993). Prostitution and male supremacy. Michigan Journal of Gender \& Law, 1, 1-12.

Goffman, E. (1959). The presentation of self in everyday life. New York: Anchor Books.

Griffith, J. D., Mitchell, S., Hart, C. L., Adams, L.T., \& Gu, L. L. (2012). Pornography 
actresses: An assessment of the damaged goods hypothesis. The Journal of Sex Research. http://dx.doi.org/10.1080/00224499.2012.719168

Hochschild, A.R. (1983). The managed heart, commercialization of human feeling. Berkeley: University of California Press.

Jeffrey, L. A., \& MacDonald, G. (2006). Sex workers in the Maritimes talk back. Vancouver \& Toronto: UBC Press.

Jeffreys, S. (1997). The idea of prostitution. North Melbourne: Spinifex Press.

Jeffreys, S. (2009). The industrial vagina: The political economy of the global sex trade. New York: Routhledge.

Koken, J.A. (2012). Independent female escort's strategies for coping with sex work related stigma. Sexuality \& Culture, 16, 209-229. http://dx.doi.org/10.1007/s12119-011-9120-3

Kontula, A. (2008). The sex worker and her pleasure. Current Sociology, 56(4), 605-620. http://dx.doi.org/10.1177/0011392108090944

Lever, J., \& Dolnic, D. (2010). Call girls and street prostitutes: Selling sex and intimacy. In Weitzer, R. (Ed.), Sex for sale: Prostitution, pornography, and the sex industry ( $2^{\text {nd }}$ ed.) (pp. 187-203). New York: Routledge.

Lucas, A. M. (2005). The work of sex work: Elite prostitutes' vocational orientations and experiences. Deviant Behavior, 26, 513-546. http://dx.doi.org/10.1080/01639620500218252

Mackinnon, C. A. (1985). Pornography, civil rights, and speech. Harvard civil rights-civil liberties. Law Review, 20, 1-70.

Messervier, H. (1999). La perception des femmes prostituées de la rue face à leur sexualité en lien avec leurs clients et leur partenaire amoureux. Rapport d'activité de maîtrise en sexologie. Montréal : Université du Québec à Montréal.

Milrod, C. \& Monto, M. A. (2012). The hobbyist and the girlfriend experience: Behaviors and preferences of male customers of internet sexual service providers. Deviant Behavior, 33(10), 792-810. http://dx.doi.org/10.1080/01639625.2012.707502

Milrod, C. \& Weitzer, R. (2012). The intimacy prism: Emotion management among the clients of escorts. Men \& Masculinities, 15(5), 447-467. http://dx.doi.org/10.1177/1097184X12452148

Oerton, S. \& Phoenix, J. (2001). Sex-bodywork: Discourses and practices. Sexualities, 4(4), 387-412. http://dx.doi.org/10.1177/136346001004004001

Orchard, T., Farr, S., Macphail, S., Wender, C., \& Young, D. (2012). Sex work in the Forest City: Experiences of sex work beginnings, types and clientele among women in London. Ontario. Sex Res Soc Policy, 9, 350-362. http://dx.doi.org/10.1007/s13178-012-0097-y

Parent, C., \& Bruckert, C. (2005). Le travail du sexe dans les établissements de services érotiques: une forme de travail marginalisé. Déviance et Société, 29(1), 33-53. 
http://dx.doi.org/10.3917/ds.291.0033

Pateman, C. (1988). The sexual contract. Oxford: Blackwells.

Pheterson, G. (1993). The whore stigma: Female dishonor and male unworthiness. Social Text, 37, pp. 39-64. http://dx.doi.org/10.2307/466259

Pryen, S. (1999). Stigmate et métier. Une approche sociologique de la prostitution de rue. Rennes : Presses Universitaires de Rennes.

Queen, C. (2002 [1997]). Real live nude girl: Chronicles of sex positive culture. San Francisco: Cleis Press.

Sanders, T. (2002). The condom as psychological barrier: Female sex workers and emotional management. Feminism \& Psychology, 12(4), 561-566. http://dx.doi.org/10.1177/0959353502012004016

Sanders, T. (2004a). A risky business. Cullompton: Willan.

Sanders, T. (2004b). Controllable laughter. Managing sex work through humour. Sociology, 38(2), 273-291. http://dx.doi.org/10.1177/0038038504040864

Sanders, T. (2005). "It's just acting": Sex workers' strategies for capitalizing on sexuality. Gender, Work and Organization, 12(4), 319-342. http://dx.doi.org/10.1111/j.1468-0432.2005.00276.x

Sanders, T. (2006). Behind the personal ads: the indoor sex markets in Britain. In R. Campbell, \& M. O'Neil (Eds.), Sex Work Now (pp. 92-115). Cullompton (UK) \& Portland (USA): Willan Publishing.

Sanders, T. (2008). Male sexual scripts: Intimacy, sexuality and pleasure in the purchase of commercial sex. Sociology, 42(3), 400-417. http://dx.doi.org/10.1177/0038038508088833

Trautner, M. N. (2005). Doing gender, doing class. The performance of sexuality in exotic dance clubs. Gender \& Society, 19(6): 771-788. http://dx.doi.org/10.1177/0891243205277253

Warr, D. J., \& Pyett, P. M. (1999). Difficult relations: Sex work, love and intimacy. Sociology of Health \& Illness, 21(3), 290-309. http://dx.doi.org/10.1111/1467-9566.00157

Weatherall, A., \& Priestley, A. (2001). A feminist discourse analysis of sex work. Feminism \& Psychology, 11(3), 323-340. http://dx.doi.org/10.1177/0959353501011003005

Welzer-Lang, D., Barbosa, O., \& Mathieu, L. (1994). Prostitution: les uns, les unes et les autres. Paris : Éditions Métailié.

Wesely, Jennifer L. (2003). Exotic dancing and the negotiation of identity: The multiple uses of body technologies. Journal of Contemporary Ethnography, 32(6): 643-669. http://dx.doi.org/10.1177/0891241603257595

Willis, E. (1992). No more nice girls. Countercultural essays. Hanover \& London: Wesleyan University Press. 


\section{Macrothink}

Journal of Social Science Studies

ISSN 2329-9150

\section{Copyright Disclaimer}

Copyright for this article is retained by the author(s), with first publication rights granted to the journal.

This is an open-access article distributed under the terms and conditions of the Creative Commons Attribution license (http://creativecommons.org/licenses/by/3.0/). 